OPEN ACCESS

Edited by:

Zvy Dubinsky,

Bar-Ilan University, Israel

Reviewed by:

Itay Cohen

Hebrew University of Jerusalem, Israel

Susana Enríquez,

National Autonomous University of

Mexico, Mexico

*Correspondence:

Milán Szabó

milan.szabo@uts.edu.au

Specialty section: This article was submitted to

Coral Reef Research,

a section of the journa

Frontiers in Marine Science

Received: 02 March 2017

Accepted: 03 August 2017

Published: 17 August 2017

Citation:

Szabó M, Larkum AWD, Suggett DJ, Vass I, Sass L, Osmond B, Zavafer A,

Ralph PJ and Chow WS (2017)

Non-intrusive Assessment of Photosystem II and Photosystem I in

Whole Coral Tissues.

Front. Mar. Sci. 4:269.

doi: 10.3389/fmars.2017.00269

\section{Non-intrusive Assessment of Photosystem II and Photosystem I in Whole Coral Tissues}

\author{
Milán Szabó ${ }^{1,2 *}$, Anthony W. D. Larkum ${ }^{1}$, David J. Suggett ${ }^{1}$, Imre Vass ${ }^{3}$, László Sass ${ }^{3}$, \\ Barry Osmond ${ }^{2,4}$, Alonso Zavafer ${ }^{2}$, Peter J. Ralph ${ }^{1}$ and Wah S. Chow ${ }^{2}$ \\ ${ }^{1}$ Climate Change Cluster (C3), University of Technology Sydney, Ultimo, NSW, Australia, ${ }^{2}$ Division of Plant Sciences, \\ Research School of Biology, Australian National University, Acton, ACT, Australia, ${ }^{3}$ Biological Research Centre, Institute of \\ Plant Biology, Hungarian Academy of Sciences, Szeged, Hungary, ${ }^{4}$ Centre for Sustainable Ecosystem Solutions, School of \\ Biological Sciences, University of Wollongong, Wollongong, NSW, Australia
}

Reef building corals (phylum Cnidaria) harbor endosymbiotic dinoflagellate algae (genus Symbiodinium) that generate photosynthetic products to fuel their host's metabolism. Non-invasive techniques such as chlorophyll (Chl) fluorescence analyses of Photosystem II (PSII) have been widely used to estimate the photosynthetic performance of Symbiodinium in hospite. However, since the spatial origin of PSIl chlorophyll fluorescence in coral tissues is uncertain, such signals give limited information on depth-integrated photosynthetic performance of the whole tissue. In contrast, detection of absorbance changes in the near infrared (NIR) region integrates signals from deeper tissue layers due to weak absorption and multiple scattering of NIR light. While extensively utilized in higher plants, NIR bio-optical techniques are seldom applied to corals. We have developed a non-intrusive measurement method to examine photochemistry of intact corals, based on redox kinetics of the primary electron donor in Photosystem I (P700) and chlorophyll fluorescence kinetics (Fast-Repetition Rate fluorometry, FRRf). Since the redox state of P700 depends on the operation of both PSI and PSII, important information can be obtained on the PSII-PSI intersystem electron transfer kinetics. Under moderate, sub-lethal heat stress treatments $\left(33^{\circ} \mathrm{C}\right.$ for $\left.\sim 20 \mathrm{~min}\right)$, the coral Pavona decussata exhibited down-regulation of PSII electron transfer kinetics, indicated by slower rates of electron transport from $Q_{A}$ to plastoquinone $(P Q)$ pool, and smaller relative size of oxidized PQ with concomitant decrease of a specifically-defined P700 kinetics area, which represents the active pool of PSII. The maximum quantum efficiency of PSII $\left(F_{v} / F_{m}\right)$ and functional absorption cross-section of PSII ( $\left.\sigma_{P S I I}\right)$ remained unchanged. Based on the coordinated response of P700 parameters and PSII-PSI electron transport properties, we propose that simple P700 kinetics parameters as employed here serve as indicators of the integrity of PSII-PSI electron transfer dynamics in corals. 


\section{INTRODUCTION}

Coral reefs are one of the world's most productive and diverse ecosystems, sustained through a symbiosis between reefbuilding corals and their endosymbiont eukaryotic microalgal partner (Symbiodinium sp.) and a complex bacterial consortia (Ainsworth et al., 2010). Nutrient exchange between partners is fuelled primarily by Symbiodinium's photosynthetic productivity and hence light utilization is a key factor driving coral metabolism from the organismal (Roth, 2014) to the entire ecological (Muir et al., 2015) reef scale. As the highly orchestrated symbiotic metabolic exchange can be threatened by several environmental stress factors that may impact coral metabolism, it is crucial to understand stress impacts at the holobiont level through integrated bio-optical/bio-physical, metabolomics and molecular approaches (Pernice and Levy, 2014). The importance of understanding the photosynthetic processes is particularly critical to revealing the light utilization efficiency and thus niche specialization of corals across a range of biogeographical habitats. Such knowledge also characterizes a range of regulatory mechanisms that respond to environmental stress that define the resilience of the coral holobiont (Roth, 2014; Warner and Suggett, 2016). Photosynthetic productivity of Symbiodinium sp. is highly regulated via the coupled inter-system electron transfer processes between photosystem II (P680) and photosystem I (P700), but the regulation mechanisms of this process in Symbiodinium are still poorly understood.

Under steady state environmental conditions, PSII and PSI work in series to ensure the linear flow of electrons from the donor side of PSII to the acceptor side of PSI, and in turn drive $\mathrm{CO}_{2}$ fixation via the Calvin-Benson Cycle. This linear electron flow is coupled with translocation of protons from the stroma to the lumen to build up a proton motive force that drives ATP synthase activity, producing a defined ratio of ATP and NADPH (e.g., Kramer and Evans, 2011). Over-reduction of the plastoquinone pool that could naturally occur under midday high irradiance levels e.g., in shallow reefs (Gorbunov et al., 2001) or as a result of impaired $\mathrm{CO}_{2}$ fixation may initiate alternative pathways of electron flow to dissipate excessive excitation energy to avoid photo-oxidative stress while maintaining coordinated level of ATP production and NADPH synthesis (Cardol et al., 2011). For Symbiodinium, these processes are much less characterized than in higher plants or green algae (Warner and Suggett, 2016), but evidence suggests that alternative electron transport can manifest itself in

Abbreviations: DCMU, 3-(3,4-dichlorophenyl)-1,1-dimethyl-urea; FR, far red light; $F_{o}$, intrinsic fluorescence signal with fully oxidized $\mathrm{Q}_{\mathrm{A}}$ in the dark; $F_{m}$, maximal fluorescence signal with fully reduced $\mathrm{Q}_{\mathrm{A}} ; F_{v}$, Variable fluorescence in the dark (proportional to reducible $\mathrm{Q}_{\mathrm{A}}$ ); GA, glycolaldehyde; $F_{v} / F_{m}$, Maximum quantum efficiency of open PSII centers in the dark based on full $\mathrm{Q}_{\mathrm{A}}$ reduction; MT, multiple turnover; LIFT-FRRF, laser-induced fluorescence transient fast repetition rate fluorometry; PAR, photosynthetically active radiation (400$700 \mathrm{~nm}$ ); PSII, photosystem II; PSI, photosystem I; P700, special chlorophyll dimer acting as the primary electron donor in PSI; $\mathrm{P} 700^{+}$, oxidized state of P700; $P_{m}$, maximum $\mathrm{P} 700^{+}$signal in weak FR light; PQ, plastoquinone pool $\sigma_{P S I I}-$ functional absorption cross section of PSII in the dark; $\mathrm{Q}_{\mathrm{A}}$, primary quinone electron acceptor in PSII; $Q_{B}$, secondary quinone electron acceptor in PS II; NIR, near infrared light; ST, single turnover. the form of cyclic electron flow (CEF) operating between PSI and the cytochrome $\mathrm{b}_{6} / \mathrm{f}$ complex possibly via the ferredoxindependent pathway (Aihara et al., 2016), or pseudo-cyclic electron flow of Mehler reaction, that plays a significant role in excess energy dissipation (Roberty et al., 2014). Expression of these pathways, however, may differ significantly between different Symbiodinium genotypes (Aihara et al., 2016; Warner and Suggett, 2016).

To characterize photosynthetic efficiency on multiple levels of organization of the symbiont algae, e.g., from free living state to single nubbins and in situ colonies, one of the most frequently applied methods is the detection of variable fluorescence of chlorophyll a (Chl a) (Warner et al., 2010). Such methods have been broadly applied to investigate light use efficiency (Gorbunov et al., 2001; Ralph et al., 2005; Szabó et al., 2014), photoacclimation (Hill and Ralph, 2005; Hennige et al., 2008; Lichtenberg et al., 2016), and photodamage (Ragni et al., 2010; Hill et al., 2011; Hill and Takahashi, 2014; Schrameyer et al., 2016) of intact corals under various environmental stress conditions. However, chlorophyll $a$ fluorescence measurements of whole coral tissues are not always straightforward due to a strong light gradient and other complex optical properties specific to coral tissues (Enríquez et al., 2005; Wangpraseurt et al., 2012, 2014; Schrameyer et al., 2014; Lichtenberg et al., 2016). Light attenuation within coral tissue is strongly wavelength dependent (Wangpraseurt et al., 2012; Szabó et al., 2014), which particularly influences both the penetration depth of the excitation light beam projected onto the coral surface and the re-absorption of the fluorescence. Attempts to overcome this fundamental problem, based on attenuation of the functional absorption-cross section of PSII $(\sigma)$ as a measure of effective irradiance within the tissue, are limited by the fact that these measurements are still performed at the coral surface thereby giving rise to potential artifacts of light attenuation of the probing and actinic light from the surface (Szabó et al., 2014). More recently, combined microfiber PAM and dissolved oxygen measurements were performed throughout the entire depth of the tissue, revealing stratification of chlorophyll $a$ fluorescence signals from different symbiont layers with potentially different photoacclimation states (Lichtenberg et al., 2016). In addition, such measurements are still fundamentally invasive and less convenient for rapid monitoring of photosynthetic performance of whole corals, and do not provide information about PSI operation and/or electron transfer, an important regulatory process of alternative electron flow processes.

Whilst past studies have applied a combination of biophysical/photobiological methods (e.g., oxygen evolution and uptake measurements, variable chlorophyll $a$ fluorescence and PSI reaction center (P700) redox kinetics) to evaluate the mechanisms underpinning photobiological operation (e.g., Suggett et al., 2008; Roberty et al., 2014; Aihara et al., 2016), most of these measurements require invasive treatment that is impractical on intact corals. Simultaneous measurements of Photosystems I and II electron transport rates [ETR(I) and ETR(II), respectively] in intact corals have been reported (Hoogenboom et al., 2012). However, their approach did not enable meaningful information to be derived about the kinetics 
of the intersystem electron transfer and the plastoquinone (PQ) pool size, which are the most significant descriptors of "active" PSII. Moreover, no assessment of the active pool of PSII based on P700 redox kinetics signal has been undertaken. P700 kinetics based on near-infrared (NIR) reflectance detection is a known whole-tissue measure for whole chain PSII and PSI electron transport e.g., in plant leaves (Jia et al., 2014), but its applicability for concerted PSII-PSI activity has not yet been evaluated in corals.

Our objective here was therefore to determine the applicability of simple P700 redox kinetic measurements to (i) assay both PSII and PSI activity, (ii) evaluate the applicability of PSI redox kinetics measurements in comparison with PSII chlorophyll $a$ fluorescence kinetics measurements and (iii) reveal the behavior of coupled PSII-PSI electron transport under acute heat stress in the common Great Barrier Reef coral Pavona decussata, which is considered a relatively heat tolerant species in terms of photosynthetic activity. Due to such high thermal tolerance, this model species allows the investigation of fine changes of photosynthetic activity under short, acute stress conditions without initiating major alterations in photosynthetic pigment content, permanent physiological damage or symbiont expulsion e.g., during coral bleaching (McClanahan, 2004; Hill et al., 2012; Krämer et al., 2013; Schrameyer et al., 2014, 2016).

We show that (i) P700 redox kinetics as applied here provide accurate estimate of both the active PSII electron pool and the steady-state and maximal levels of $\mathrm{P} \mathrm{O}^{+}$and (ii) sub-lethal heat stress impacts the redox state of $\mathrm{P} 700^{+}$and PSII electron transfer processes, maintaining an enhanced electron turnover via PSI, even when linear electron flow from PSII is transiently impaired.

\section{MATERIALS AND METHODS}

\section{Coral Material}

Colonies of the coral species $P$. decussata (Dana) were collected from Heron Island lagoon, located on the southern Great Barrier Reef of Australia $\left(151^{\circ} 55^{\prime} \mathrm{E}, 23^{\circ} 270^{\prime} \mathrm{S}\right)$ during July 2015. Prior to experimentation, coral colonies were maintained for 4-6 months in a recirculating 500-L aquarium at the University of Technology Sydney under constant temperature of $25^{\circ} \mathrm{C}$, salinity of $32 \mathrm{ppt}$, and irradiance of $150 \mu \mathrm{mol}$ photons $\mathrm{m}^{-2} \mathrm{~s}^{-1}$ (provided by Hydra FiftyTwo HD LED array, Aquaillumination ${ }^{\circledR}, \mathrm{C} 2$ Development, Inc., USA) on a $12 \mathrm{~h}: 12 \mathrm{~h}$ light:dark cycle. Before all measurements, $P$. decussata fragments $(2-4 \mathrm{~cm})$ were cut from the parent colonies and maintained for at least $12 \mathrm{~h}$ in $10-\mathrm{L}$ aquaria aerated by bubbling of ambient air at $25^{\circ} \mathrm{C}$ and irradiance of $150 \mu$ mol photons $\mathrm{m}^{-2} \mathrm{~s}^{-1}$.

For experimental treatments, coral nubbins were transiently moved to an optical glass cuvette $(4 \times 4 \times 4 \mathrm{~cm}$, Hellma Inc. $)$ filled with seawater and constantly aerated with an air pump at a temperature of $25^{\circ} \mathrm{C}$ (control conditions) or set to a desired temperature using a heater/chiller (Julabo Ltd.) as described in the heat treatment section.

\section{Simultaneous Measurements of PSII and PSI Photosynthetic Electron Transport}

In order to measure the operation of PSII and PSI reaction center simultaneously, PSII chlorophyll fluorescence parameters (described in details in "Active chlorophyll a fluorometry") and P700 kinetics (described in details in "Measurement of redox kinetics of $P 700$ " section) were recorded on the same spot of the same specimen, and under identical conditions (the configuration of the setup is shown in Figure S1). This was achieved using a multi-furcated fiber optics light-guide (Heinz Walz GmbH, Effeltrich, Germany) that integrated various probing light sources into a single light-guide aligned to the coral nubbin within the cuvette (described in "Coral material" section). The same multi-furcated fiber optic system also served for guiding P700/fluorescence signals to the chlorophyll fluorescence detectors and P700 emitter-detector unit. With this setup (Figure S1), potential artifacts resulting from differences in optical geometry and measuring conditions were minimized.

\section{Measurement of Redox Kinetics of P700}

Measurement of P700 redox changes in the current study is based on the principle that absorbance changes at $\sim 820 \mathrm{~nm}$ are related to changes in redox levels of the photosystem I reaction center P700, varying between 100\% reduced (P700) and 100\% oxidized $\left(\mathrm{P} 70^{+}\right)$states (Klughammer and Schreiber, 1994). The lowest signal level is related to $100 \%$ reduced P700, which upon application of far-red background light, is oxidized to the steadystate $\mathrm{P} 700^{+}$level. Upon application of a saturation pulse (usually of white light that saturates both PSII and PSI), P700 becomes fully oxidized, representing $100 \% \mathrm{P} 70^{+}$. After cessation of the saturation pulse, electron flow from PSII reduces $\mathrm{P} 700^{+}$, lowering the signal levels usually below the initial steady-state P700 level (because of the strong reducing pressure of electrons from PSII electrons, if active). With the far-red light continuously turned on, P700 is re-oxidized to the given steady state level. The corresponding changes in absorbance were monitored using a dual wavelength $(820 / 870 \mathrm{~nm})$ unit (ED-P700DW) attached to a pulse amplitude modulation (PAM) fluorometer (Heinz Walz $\mathrm{GmbH}$, Effeltrich, Germany) in reflectance mode, in a custom made setup that synchronizes illumination and data acquisition using a multi-channel programmable pulse/delay generator, as described in details previously (Kou et al., 2013).

The amount of photo-oxidisable P700 was initially obtained by illuminating each coral nubbin with continuous far-red light illumination $\left(\sim 200 \mu \mathrm{mol}\right.$ photons $\mathrm{m}^{-2} \mathrm{~s}^{-1}$, peak wavelength 740 $\mathrm{nm}$, from an LED735-66-60 diode array, Roithner LaserTechnik, Vienna, Austria) for $\sim 10$ s to reach steady-state P700 oxidation. A measuring sequence was then initiated, which consisted of (i) a $50 \mathrm{~ms}$ delay phase to record the steady-state $\mathrm{P} 700^{+}$, (ii) a single-turnover saturating xenon flash (ST, irradiance $>10^{6} \mu \mathrm{mol}$ photons $\mathrm{m}^{-2} \mathrm{~s}^{-1}$, Heinz Walz GmbH, Effeltrich, Germany) to fully photo-oxidize P700 to form $100 \% \mathrm{P} 700^{+}$and (iii) a subsequent 900 ms phase to record P700 redox kinetics changes after cessation of the saturation pulse, but with background far-red light continuously present during the entire cycle. The peak level of the signal immediately after the saturation flash was denoted as $P_{m}$, representing the maximum photo-oxidisable P700. P700 kinetics signals following the saturation pulse were analyzed using a mathematical integration of the area that is bounded by the horizontal line representing the initial and final steady-state $\mathrm{P} 700^{+}$levels in continuous far-red light, and the dipping curve representing the transient reduction of $\mathrm{P} 700^{+}$by 
electrons donated by PSII after a saturating flash-termed the "P700 kinetics area" for short (Kou et al., 2012; Hu et al., 2013; Fan et al., 2016b). One measuring cycle lasted for $950 \mathrm{~ms}$, and 8 sequences, at $0.2 \mathrm{~Hz}$, were averaged into a single trace to improve signal-to-noise.

\section{Active Chlorophyll a Fluorometry}

Variable chlorophyll fluorescence parameters were determined by Fast-Repetition Rate fluorometry (LIFT-FRRf, Soliense Inc.) using the " $\mathrm{Q}_{\mathrm{A}}$ flash excitation" protocol, based on single turnover (ST) flashes. The instrument and the principle of the $\mathrm{Q}_{\mathrm{A}}$ flash excitation protocol are described in detail Osmond et al. (2017). Briefly, excitation light provided by a blue LED ( $\sim 470 \mathrm{~nm}$ peak wavelength) is focused by the custom-built, $12 \mathrm{~cm}$ aperture telescope onto a $\sim 2 \mathrm{~cm}$ diameter spot that was aligned with one of the entry arms of the fiber-optics used for P700 and PAM measurements, providing a combined exit point of the fiberoptics facing the coral sample side (described above). The $\mathrm{Q}_{\mathrm{A}}$ flash excitation protocol from the LIFT-FRRf marine instrument applied $\sim 1 \mu$ s flashlets of blue excitation light in a saturation sequence of 180 flashlets at $50 \%$ duty cycle (average excitation power of about $6300 \mu \mathrm{mol}$ photons $\mathrm{m}^{-2} \mathrm{~s}^{-1}$ ), spaced at 2 $\mu \mathrm{s}$ intervals, and a relaxation sequence with 90 flashlets with exponentially increasing intervals starting at $20 \mu \mathrm{s}$, resulting in a $362 \mu \mathrm{s}$ long saturation sequence and a $28788 \mu \mathrm{s}$ long relaxation sequence $(29150 \mu \mathrm{s}$ in total). The same telescope collected the red chlorophyll fluorescence signal, separated from the $470 \mathrm{~nm}$ excitation light using a $45^{\circ}$ dichroic mirror (Edmund Optics NT47-948) and conveyed by a $12.5 \mathrm{~mm}$ diameter flexible $1 \mathrm{~m}$ optical fiber to the detector unit of the instrument. A 685 $\mathrm{nm}$ interference filter (25 $\mathrm{nm}$ bandwidth, $75 \%$ transmission; custom-made by Intor Inc.) further separated the chlorophyll fluorescence emission from the reflected excitation light.

The $\mathrm{Q}_{\mathrm{A}}$ flash-induced fluorescence changes were analyzed using the automated fitting algorithm of the Soliense software (http://soliense.com/LIFT_Method.php) according to the biophysical FRR model of Kolber et al. (1998). The variable fluorescence yield, $F_{v}$ is calculated as $F_{v}=F_{m}-F_{o}$, where $F_{o}$ is minimal fluorescence and $F_{m}$ is maximal fluorescence with fully reduced $\mathrm{Q}_{\mathrm{A}}$. The maximum photochemical efficiency of PSII is thus expressed as $F_{v} / F_{m}$. In addition, the functional absorption cross-section of PSII $\left(\sigma_{P S I I}\right)$, the kinetics of electron transport between PSII and PSI and the oxidized portion of PQ pool were estimated by fitting the LIFT-FRR fluorescence transients to the FRR model [http://soliense.com/LIFT_Method.php, "Size of the oxidized portion of PQ pool ( $\left.\mathrm{PQ}_{\mathrm{ox}}\right)$ "]. The decline in fluorescence yield during the relaxation of $\mathrm{Q}_{\mathrm{A}}$ flash acquisition is fitted by two exponentials $\left(\tau_{1}\right.$ and $\tau_{2}$ ) corresponding to the half times for electron transfer from faster component (in plants commonly referred as $\mathrm{Q}_{\mathrm{A}}$ to the $\mathrm{PQ}$ ) and slower component (in plants commonly referred as PQ pool to PSI, respectively, Osmond et al., 2017; and http://soliense.com/LIFT_Method. php).

Another method to monitor chlorophyll fluorescence is the so called OJIP protocol or the Kautsky induction curve or the polyphasic rise of chlorophyll fluorescence. This method consists of monitoring the kinetics of the chlorophyll induction curve in the transition between dark to light adapted state (Kalaji et al., 2017). This protocol primary measures the transition between the point where all PSII reaction center are open (refer as $\mathrm{O}$ step or $F_{o}$ at $20 \mu \mathrm{s}$ ) to the point where all reaction centers are closed and the fluorescence intensity reaches its maximum, nominally called Peak (refer as P step or $F_{m}$ ) (Strasser, 1992). Additionally, two inflections can be observed at $2 \mathrm{~ms}$ (J step) and at $20 \mathrm{~ms}$ (I step). These four steps delimit three phases: OJ, JI and IP and conventionally it is believed that they are associated with events in the electron transport chain (ETC) (Strasser, 1992; Kalaji et al., 2017). The OJ, photochemical phase, relates to the reduction of the acceptor side of PSII (Strasser, 1992). The JI phase relates to the transport beyond $\mathrm{Q}_{\mathrm{A}}$ and IP phase relates to several processes, in particular the electrons reaching PSI (Schansker et al., 2005; Kalaji et al., 2017). The induction curve of the chlorophyll $a$ fluorescence (OJIP transient) was measured at $25^{\circ} \mathrm{C}$ using a Multichannel-Plant Efficiency Analyzer 2 (M-PEA, Hansatech Instruments, UK) (for a full description of the instrument refer to Strasser et al., 2010). The excitation, saturating and actinic light was $660 \mathrm{~nm}$ with an intensity of 5000 photons $\mathrm{m}^{-2} \mathrm{~s}^{-1}$ for $10 \mathrm{~s}$. Fragments of corals were placed in an optical glass cuvette (described in "Coral material") filled with seawater. The cuvette was placed in front of the sensor head without the use of a leaf clip. To increase the light homogeneity within the sample holder, the cuvette was covered in aluminum foil. The sample was kept in darkness for $10 \mathrm{~min}$ with constant air bubbling.

\section{Heat Stress and Recovery Experiment}

Coral nubbins $(n=3)$ in the optical glass cuvette were darkacclimated at $25^{\circ} \mathrm{C}$ for $10 \mathrm{~min}$ under continuous aeration to measure $P_{m}$, the P700 kinetics area, steady-state $\mathrm{P} 700^{+}$and $F_{v} / F_{m}$ in the dark-acclimated state (denoted as "control"). After recording photophysiological parameters in the "control" phase, the temperature was elevated to $33^{\circ} \mathrm{C}$ within $\sim 15 \mathrm{~min}$. Following $20 \mathrm{~min}$ of elevated temperature treatment, the effects of the heat stress were recorded (denoted as "heat"). Samples were then returned to $25^{\circ} \mathrm{C}$ within $\sim 15 \mathrm{~min}$, and after a further $20 \mathrm{~min}$, the measurement sequence was repeated (denoted as "recovery"). In order to avoid any potential changes in the electron transport chain due to long dark acclimation periods (Hill and Ralph, 2008), samples were kept at growth irradiance $\sim 100 \mu \mathrm{mol}$ photons $\mathrm{m}^{-2} \mathrm{~s}^{-1}$ of white light under constant aeration in the same optical glass cuvette throughout. This background light was kept on for the entire experiment, during the control, heat and recovery measurements, except the 10 min dark adaptation periods where the maximum quantum yield and the dark adapted P700 parameters were recorded. Measurements were performed through the fiber optic system on the same spot for the control, heat treatment and recovery phases, on three separate nubbins (independent biological replicates).

\section{Inhibitor Treatments}

Pavona decussata nubbins were first measured without the application of any inhibitor to determine baseline responses. Various chemical inhibitors were then added directly to the seawater surrounding the nubbins during the 
control measurements. DCMU (3-(3,4-dichlorophenyl)-1,1dimethylurea) was applied at a final concentration of $40 \mu \mathrm{M}$ in complete darkness for $\sim 20$ min, after which P700 measurements were performed. In the case of DCMU treatment, a combined heat treatment was also performed as described above ("Heat stress and recovery"). In a second experiment, the CalvinBenson cycle inhibitor glycolaldehyde (GA) was applied at a final concentration of $5 \mathrm{mM}$ in the same manner as for DCMU.

\section{Statistical Analyses}

Paired Sample $t$-test was applied for paired comparisons of parameter means (specified in Results) of heat-treated and control samples (with equal variances) using Origin Pro 9.1 (Origin, USA).

\section{RESULTS}

\section{P700 Redox Kinetics under Heat Stress and Recovery}

Steady-state $\mathrm{P} 700^{+}$reflects the actual oxidized level of the $\mathrm{P} 700^{+}$pool under weak far-red illumination, which attained the maximal level of $\mathrm{P} 700^{+}\left(P_{m}\right)$ upon receiving a strong saturation pulse (SP). As a result of the high intensity of the saturation pulse, electron flow from PSII led to the re-reduction of $\mathrm{P}^{2} 00^{+}$, with a decline in $\mathrm{P} 700^{+}$below the initial steady-state $\mathrm{P} 700^{+}$. As the background FR light was continuously on, $\mathrm{P} 700^{+}$increased again (due to the reoxidation of P700) and within $\sim 1000 \mathrm{~ms}$ attained a steady-state level. In the same specimen, under heat stress, the $\mathrm{P} 700^{+}$trace exhibited similar pattern; however, the initial $\mathrm{P}_{700}{ }^{+}$level decreased and the P700 kinetics area became smaller, indicating slowing of electron flow from PSII under heat stress. These changes partially recovered to the original level upon cooling back to $25^{\circ} \mathrm{C}$ (Figure 1, representative traces).

As the absolute values of $P_{m}$, steady-state $\mathrm{P} 0^{+}$and P700 kinetics area varies from specimen to specimen due to potential differences in symbiont density and optical properties etc., heat induced changes in P700 parameters are represented as relative changes (Figure 2). $P_{m}$ significantly declined by $\sim 25 \%$ under heat stress and did not fully recover after the stress removal, compared to the untreated control (Figure 2A). Steady-state $\mathrm{P} 700^{+}$significantly declined by $\sim 50 \%$ and recovered to $\sim 80 \%$ of the untreated control values (Figure 2B). P700 kinetics area significantly declined by $\sim 50 \%$ and exhibited only a partial recovery to $\sim 70 \%$ of the untreated control (Figure $2 \mathrm{C}$ ). These trends suggest overall that the reduced form of PSI (i.e., less $\mathrm{P} 700^{+}$) is more prevalent under acute heat stress.

\section{P700 Redox Kinetics under Heat Stress Conditions, When Linear Electron Flow was Chemically Inhibited by DCMU}

Under acute heat stress $\mathrm{P} 700^{+}$decreased; however, under these conditions it was not possible to judge to what extent linear electron flow from PSII might have contributed to redox changes of $\mathrm{P} 700^{+}$. Therefore, in order to investigate the behavior of P700 kinetics independently from PSII processes, the heat treatment experiment was performed on coral fragments when

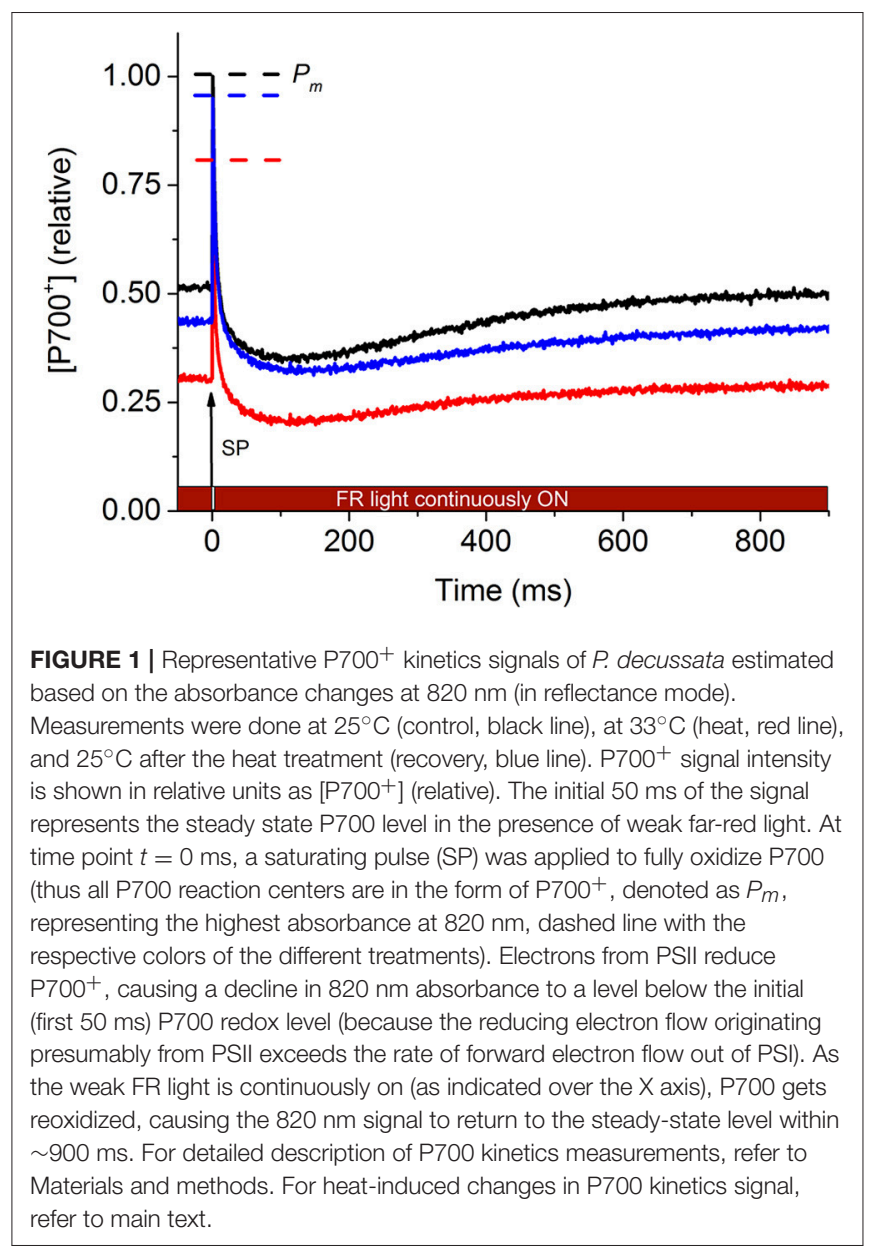

the linear electron flow was chemically blocked with DCMU (Jones et al., 2003). Treatment of $P$. decussata nubbins with DCMU completely eliminated the P700 kinetics area below the steady level (at $25^{\circ} \mathrm{C}$ ) (Figure 3).

The parameter $P_{m}$ did not change significantly with DCMU and heat treatment (Figure 4A). Steady-state $\mathrm{P} 00^{+}$significantly increased by $\sim 45 \%$ upon DCMU treatment (at $25^{\circ} \mathrm{C}$, Figure $4 \mathrm{~B}$ ), indicating elevated $\mathrm{P} 700^{+}$. In the presence of DCMU, heat treatment caused a reversible decline in steady-state $\mathrm{P} 700^{+}$by $\sim 15 \%$; however these changes were not statistically significant as compared to non-heat treated but DCMU treated samples.

\section{P700 Kinetics after Chemically Blocking Calvin-Benson Cycle}

We further investigated whether the changes in $\mathrm{P} 700^{+}$redox state could be related to the operation of Calvin-Benson cycle. This was performed by incubating coral fragments with the Calvin-Benson cycle inhibitor glycolaldehyde (GA). GA induced a decrease in the steady-state $\mathrm{P} 700^{+}$levels and P700 kinetics area at the initial time points; upon prolonged incubation the P700 kinetics area completely disappeared (Figure 5), indicating that GA inhibition of Calvin-Benson cycle perturbs the photosynthetic pathways in a similar manner as heat stress, i.e., 

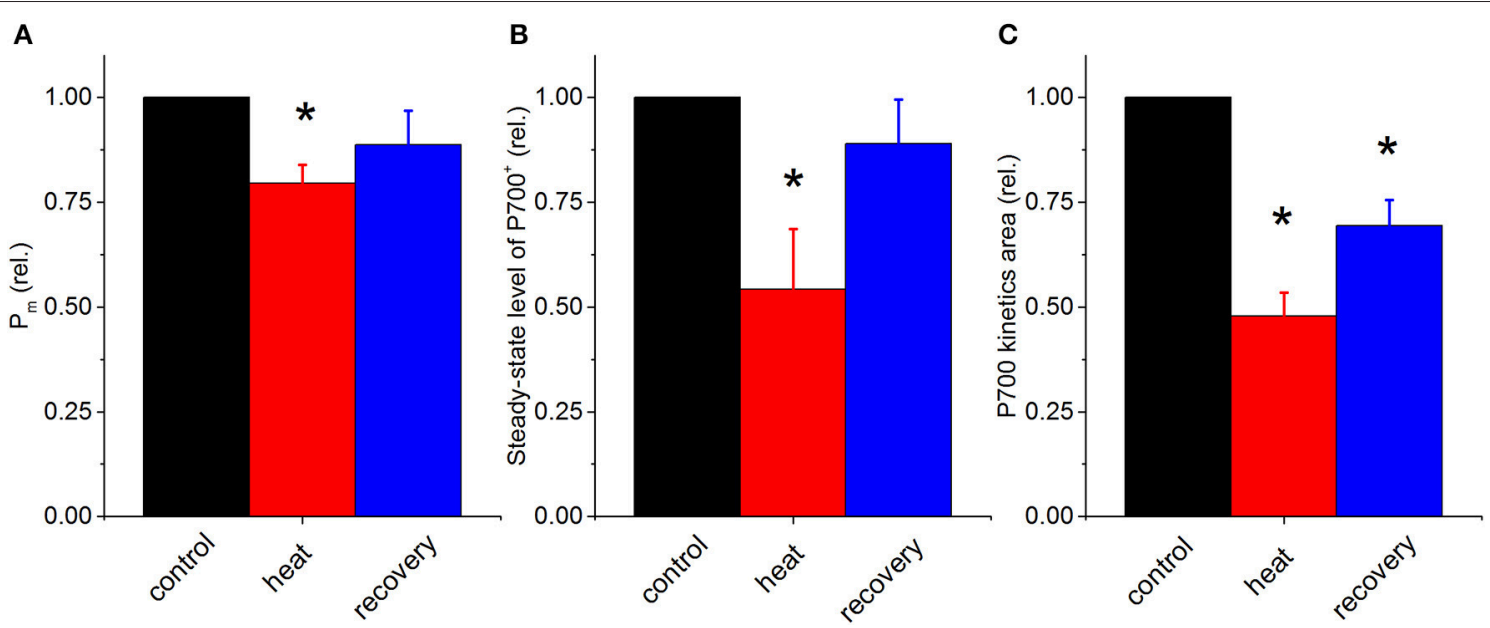

FIGURE 2 | Relative changes in P700 parameters in the coral $P$. decussata over the course of heat treatment and recovery period. $P_{m}$ (A), initial steady-state level of $\mathrm{P} 700+^{+} \mathbf{( B )}$, and the values of P700 kinetics area ("PSIl area") (C); control, black column; heat treatment, red column and recovery, blue column. Signals were recorded on the same samples under the same temperature treatment as described in Figure 1. Statistically significant differences of parameters between control and treatment $(p<0.05)$ are denoted with asterisks. Error bars are standard errors of mean $(\mathrm{SEM}), n=3$.

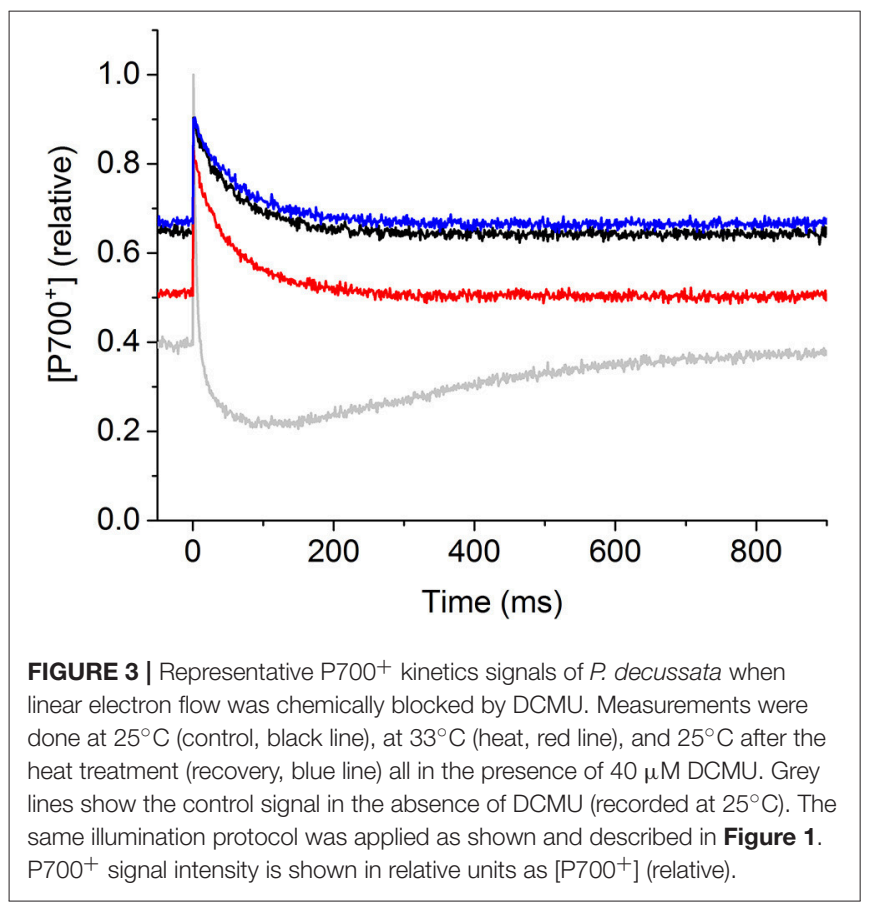

more reduced state of PSI and decreased electron flow from PSII to PSI; however the effect of chemical inhibition by GA was more pronounced than that of the acute heat stress (see Discussion).

\section{Fast-Repetition Rate Fluorescence (FRRf) and Fast Induction Curve (OJIP) Parameters under Heat Stress}

In order to investigate the PSII electron transfer kinetics under heat stress alongside PSI, under the same conditions as for the P700 measurements, fast fluorescence induction-relaxation chlorophyll fluorescence measurements were performed. Small changes could be observed in fluorescence kinetics during the saturation phase of the FRRf signal in heat stressed relative to control fragments (Figure 6); the calculated parameters, maximum quantum efficiency of PSII $\left(F_{v} / F_{m}\right)$ (Figure 7A) and functional absorption cross-section $\left(\sigma_{P S I I}\right)$ (Figure 7B), did not change significantly, indicative of unaltered inherent properties of PSII reaction centers. In contrast, more substantial changes were observed during the relaxation phase of the fluorescence kinetics (Figure 6), as the relative oxidation state of the PQ pool significantly declined (i.e., the PQ pool became more reduced) (Figure 7C). Consistent with this, although the forward electron transfer time constant component $\tau_{1}$ increased upon heating, this change was not significant (Figure 7D), whereas the longer relaxation time constant component, $\tau_{2}$ increased significantly upon heat stress and partially recovered (Figure 7E), indicative of slowing electron transport rates between the PQ pool and PSI. This effect was largely reversed after recovery at $25^{\circ} \mathrm{C}$.

Additional multi-phasic fast induction chlorophyll fluorescence measurements were performed to reveal the relative changes in the various phases of fluorescence rise during a multiple turnover saturating flash (Figure 8). In the double normalized curves, $F_{o}$ (the "O" phase) is set to 0 , whereas $F_{m}$ (the "P" phase) is set to 1 to display relative changes. "Control" curve shows a typical OJIP rise of corals, with a distinguishable OJ phase $\left(10^{-5}\right.$ to $\left.2 \times 10^{-3} \mathrm{~s}\right)$ representing the photochemical phase of $\mathrm{Q}_{\mathrm{A}}$ reduction to $\mathrm{Q}_{\mathrm{A}}^{-}$and the JI $\left(2 \times 10^{-3}\right.$ to $10^{-1}$ s) and IP $\left(10^{-1}\right.$ to $\left.2 \times 10^{0} \mathrm{~s}\right)$ phases representing the thermal phase of fluorescence induction (e.g., Hill et al., 2004a). In heat treated samples, the fluorescence rise is almost complete already at the J phase, whereas the JIP phase largely disappeared. Under recovery conditions, the OJIP fluorescence induction curve regained its original characteristics of control samples, but the recovery was only partial. 

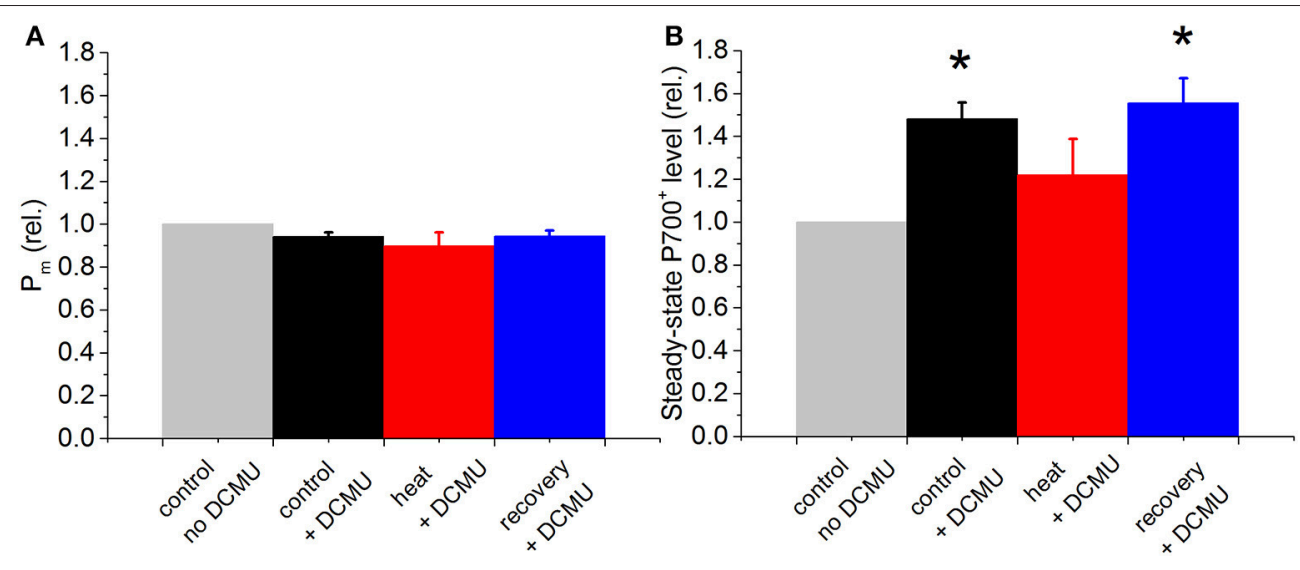

FIGURE 4 | Relative changes in P700 kinetics signals in the coral $P$. decussata over the course of heat treatment and recovery period, in the presence of DCMU. $P m$ (A), and initial steady-state level of $\mathrm{P} 700^{+}$(B) were recorded on the same dark-adapted samples, at the same time point. Control, black column; heat treatment, red column and recovery, blue column. Gray bars show the signal in the absence of DCMU, normalized to 1, to show relative changes caused by the treatments. Signals were recorded on the same samples under the same temperature treatment as described for Figure. Statistically significant differences between -DCMU and + DCMU control samples $(p<0.05)$ are shown with asterisk. Error bars are standard errors of mean $(\mathrm{SEM}), n=3$.

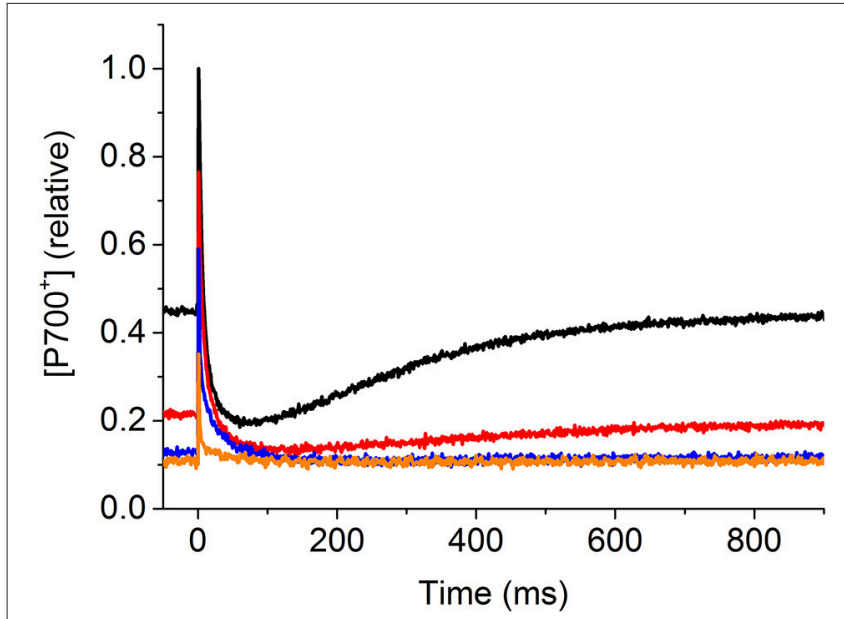

FIGURE 5 | Effect of the Calvin-Benson cycle inhibitor glycolaldehyde (GA) on P700 kinetics. Control nubbins were measured in the absence of the inhibitor (-GA, black line), then the same nubbins were incubated with $5 \mathrm{mM}$ GA (+GA) and P700 measurements were performed at different time points: 50 min, red line; 2 h, blue line; 4.5 h, orange line. The same illumination protocol was applied as shown and described in Figure 1. P700+ signal intensity is shown in relative units as $\left[{\left.\mathrm{P} 700^{+}\right]}\right.$(relative).

\section{DISCUSSION}

Photosynthetic performance of reef-building corals plays a key role in determining their ecological success under normal growth conditions as well as in response to transient stressors (Warner et al., 2002; Anthony et al., 2007). Photobiological performance and photosynthetic energy budgets of Symbiodinium in hospite have been characterized and reviewed in several studies (Brodersen et al., 2014; Roth, 2014; Warner and Suggett, 2016). However, surprisingly, the available data regarding the fundamental intersystem PSII-PSI electron transport properties

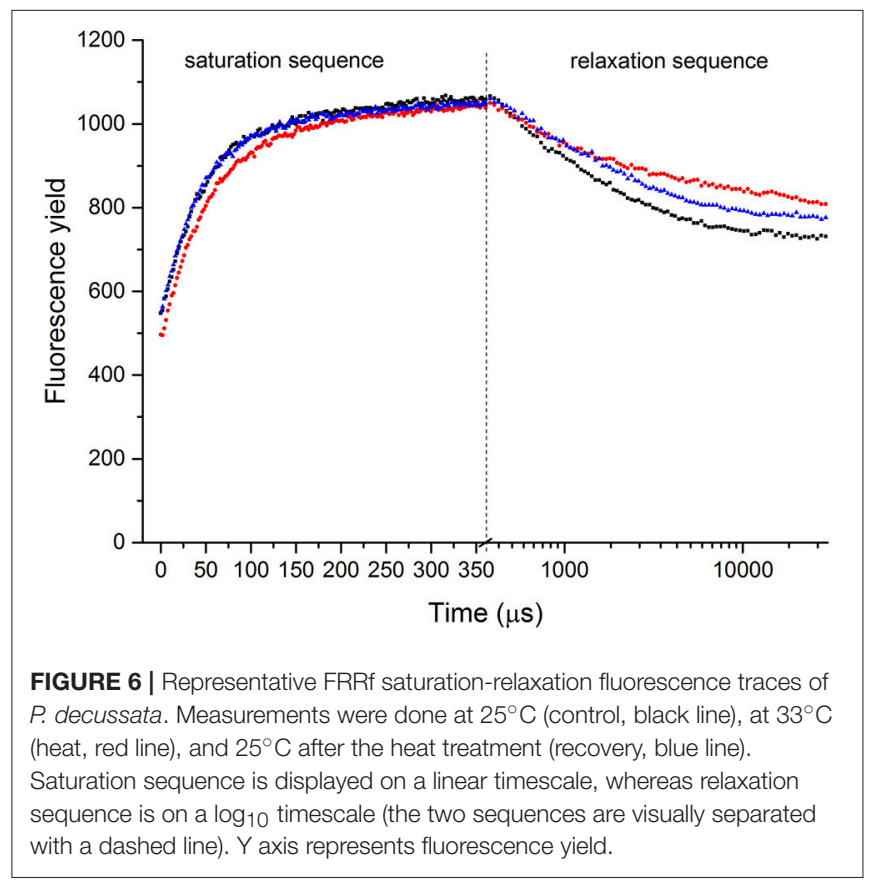

in corals is scarce. While changes in PSII activity represent one of the best known indicators of heat stress sensitivity (Warner et al., 1999; Hill et al., 2004b), the loss of PSII quantum efficiency, deduced from variable Chl fluorescence measurements, usually manifests itself under severe prolonged heat impacts which lead to extensive loss of photosynthetic performance (e.g., Hill et al., 2012). Intuitively, severe inhibition of PSII activity should be preceded by more subtle temperature perturbations of the electron transport flow through the whole photosynthetic machinery, lowering photosynthetic performance. Such 


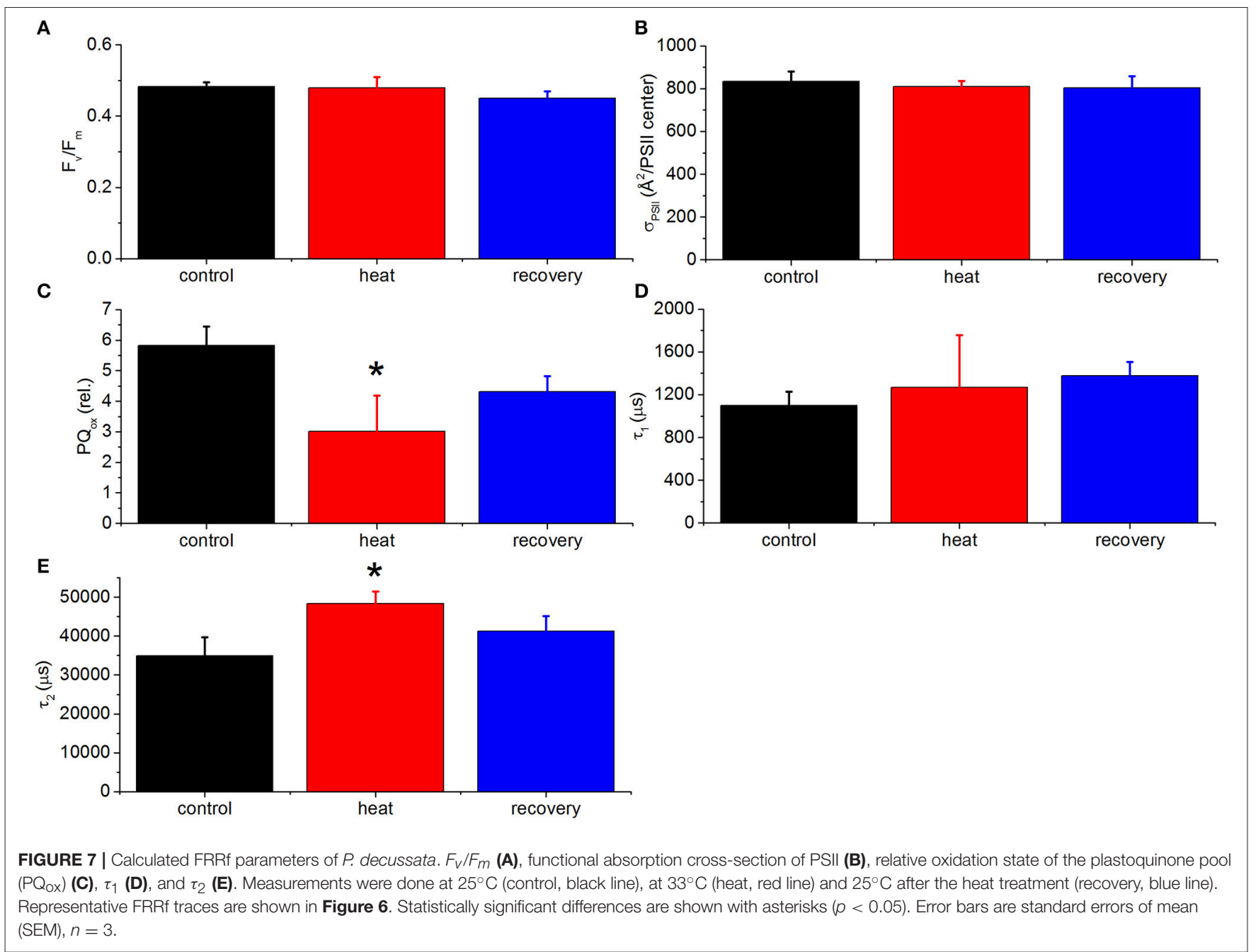

decline in photosynthetic activity, if persistent, may lead to a gradual deterioration of the photosynthetic performance of the endosymbiont algae without impacting the most characteristic indicator of the stress, the decline in PSII quantum efficiency. Unfortunately, the PSII quantum efficiency is generally used as the most universal (and in most cases the only) indicator of the stress presence in corals. Earlier studies (Hoogenboom et al., 2012) indicated that PSII is a more vulnerable component to heat stress than PSI, which is in agreement with our finding that forward electron transfer kinetics slow down (Figure 7). However, the main aim of our approach was to ascertain whether using a single measurement of P700 redox kinetics yields information about both active PSII and PSI, possibly complementing the performance indicators obtained by more commonly applied chlorophyll fluorescence measurements.

The fact that acute heat stress caused remarkable changes in P700 kinetics, the steady-state level of $\mathrm{P} 700^{+}$and the P700 kinetics area suggests that electron flow from PSII has a strong impact on the redox state of $\mathrm{P} 700^{+}$, similarly to the situation in higher plants (Oguchi et al., 2011; Jia et al., 2014). This is corroborated with the observations that the P700 kinetics area completely disappeared in the presence of DCMU (Figure 3) and the steady state $\mathrm{P} 00^{+}$increased, as the linear electron flow from PSII reducing $\mathrm{P} 700^{+}$has completely stopped. When heat stress was applied in the presence of DCMU, the steady-state $\mathrm{P} 700^{+}$ decreased, although to a much lesser extent as compared to the heat treatment in the absence of inhibitor (cf. Figures 2, 4). The fact that the steady-state $\mathrm{P} 700^{+}$level drops even in the presence of DCMU (when linear electron flow is blocked) indicates that alternative electron transport pathways might have been initiated under heat stress, the existence of which has been shown in Symbiodinium (Reynolds et al., 2008; Roberty et al., 2014; Aihara et al., 2016). The diminished response of steady-state $\mathrm{P} 700^{+}$ under heat stress, when DCMU was applied might be due to the disturbance of the redox poise of P700 by DCMU (Fan et al., 2016a). Our chlorophyll fluorescence measurements indicated that under moderate heat stress conditions, maximum PSII quantum efficiency and the functional cross-section of PSII were marginally affected by the heat stress. Instead, kinetic parameters of the photosynthetic electron transport responded to a higher degree. In plants, $\tau_{1}$ reflects electron transport from $\mathrm{Q}_{\mathrm{A}}$ to $\mathrm{PQ}$, whereas $\tau_{2}$ reflects a slower electron transfer component from 


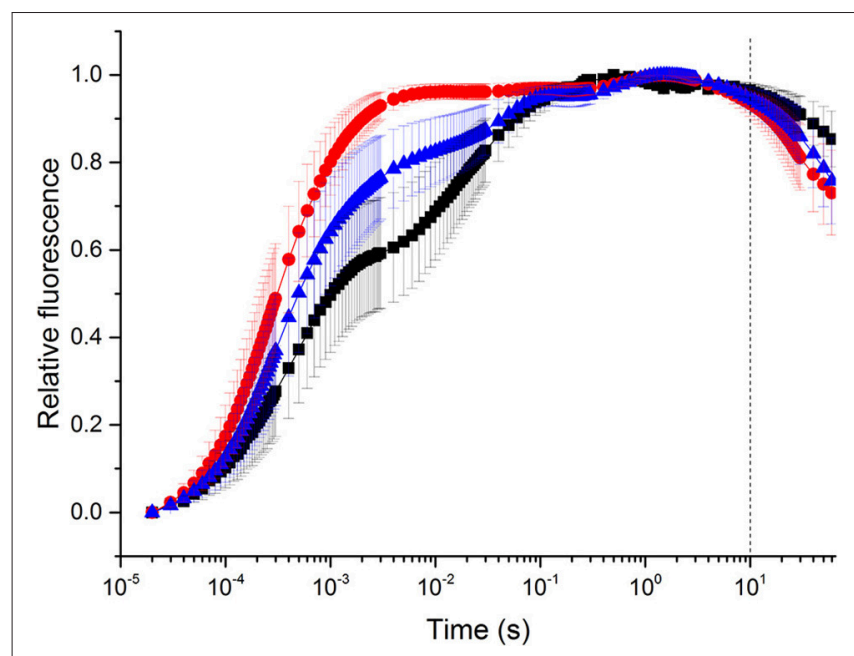

FIGURE 8 | Fast fluorescence induction (OJIP) curves. Measurements were done at $25^{\circ} \mathrm{C}$ (control, black line), at $33^{\circ} \mathrm{C}$ (heat, red line), and $25^{\circ} \mathrm{C}$ after the heat treatment (recovery, blue line). Illumination was applied from the beginning of data recording; the dashed line represents the timepoint when the

illumination was turned off. Fluorescence traces are double-normalized $\left(F_{O}\right.$ set to 0 and $F_{m}$ to 1 ) in order to represent relative changes. Error bars are standard errors of mean (SEM), $n=3$.

PQ to PSI (Osmond et al., 2017). However, these electron transfer steps are uncharacterised in detail for corals; as such, here we refer to $\tau_{1}$ as the fast component of electron transfer, an inherent property of PSII, which is largely unchanged under acute heat stress. In contrast, $\tau_{2}$ is most likely closely related to the reduction level of the PQ pool (and possibly the electron transfer steps beyond PQ pool, indicated by the large time constant values), which is related to the phenomenon that the $\mathrm{Q}_{\mathrm{B}}$ site is occupied by an electron that is unable to proceed to the PQ pool, because an oxidized PQ molecule from the PQ pool is unavailable. This is corroborated by the calculated oxidized portion of the PQ pool, which strongly declined upon heating. The concentration of oxidized PQ decreases when the PQ pool is more reduced due to limitation of electron transport at the acceptor side of PSI. This is in agreement with earlier findings that persistent reduction of the PQ pool was more prevalent under heat stress or bleaching conditions (Jones and Hoegh-Guldberg, 2001; Hill et al., 2004a).

This interpretation is further corroborated by the finding that when active electron flow from PSII to PSI is impaired under heat stress, maximal fluorescence of the fast induction (OJIP) curves occurs already at the J level, $\sim 2 \mathrm{~ms}$, with only a small thermal phase (JIP) present. Together these measurements indicate that the maximal photochemical capacity of PSII reaction centers is not affected (unchanged $F_{v} / F_{m}$ and presence of photochemical OJ phase) under moderate heat stress, whereas the subsequent electron transfer steps became significantly impaired probably due to the heat-induced reduction of the PQ pool, as has been shown for higher plants (Tóth et al., 2007). Taken together, our observations suggest that when referring to the "active PSII electron transfer" involved in reducing $\mathrm{P} 700^{+}$, the critical steps appear to be the efficiency of electron transfer after the primary acceptor, $\mathrm{Q}_{\mathrm{A}}^{-}$, rather than the actual photochemical activity of PSII reaction centers (represented by the presence of OJ phase). While $F_{v} / F_{m}$ measurements indicated little stress, the simultaneous measurements of PSII to PSI electron transfer rates clearly indicated severe impacts on the PSII-PSI intersystem electron flow, i.e. the forward electron transfer from $\mathrm{Q}_{A}$ to $\mathrm{Q}_{\mathrm{B}}$ and the PQ pool. Steady-state $\mathrm{P} 700^{+}$levels recorded at $820 \mathrm{~nm}$, in the presence of weak FR light $(740 \mathrm{~nm})$ were very sensitive to heat-induced changes, indicating that under acute heat stress there is less $\mathrm{P} 700^{+}$under continuous weak FR light, possibly due to enhanced electron pressure, which may originate from non-linear electron flow pathways.

The P700 kinetics signal underwent similar changes to heat stress when chemical inhibition of the Calvin-Benson cycle was applied. Glycolaldehyde (GA) is a known inhibitor of Calvin-Benson cycle in corals (Bhagooli, 2013; Hill et al., 2014) and earlier applications have demonstrated that under conditions when $\mathrm{CO}_{2}$ fixation is impaired by chemical inhibition (Hill et al., 2014) or by decreased concentrations of dissolved inorganic carbon (Oakley et al., 2014), linear electron flow of photosynthesis is downregulated even at ambient temperatures in the absence of heat stress (Hill et al., 2014; Oakley et al., 2014). Such a response is in agreement with the current study, where P700 kinetics area (bounded by the horizontal line corresponding to steady-state illumination with far-red light and the dipping curve of $\mathrm{P} 700^{+}$signal upon application of a saturating flash, representing the delivery of PSII electrons to PSI), completely disappears in the presence of GA, but in the absence of heat stress (Figure 5), in agreement with earlier findings on decreased oxygen evolution in corals as a result of GA treatment (Hill et al., 2014). In parallel with the loss of P700 kinetics area, the initial steady-state P700 level decreases, possibly because inhibition of Calvin-Benson cycle leads to elevated NADPH and ferredoxin levels that cause over-reduction of PQ pool through cyclic electron transport pathway(s) and blockage of the PSI acceptor side. This in fact leads to more reduced P700 (lower steady-state $\mathrm{P} 700^{+}$) and slower electron transfer rates (smaller P700 kinetics area). Therefore, GA treatment alone mimics the heat-induced changes in photosynthetic electron flow, but the acute heat stress applied in the current study may cause only partial inactivation of Calvin cycle (P700 kinetics area not completely lost), which can be recovered during the applied recovery period at $26^{\circ} \mathrm{C}$. As for all dinoflagellates, Symbiodinium sp. carry a type II Rubisco (Whitney et al., 1995) that is considered generally more heat sensitive than type I Rubisco (Leggat et al., 2004). The same heat stress assay employed here was applied in earlier studies to cause partial inactivation of Rubisco in Symbiodinium (Lilley et al., 2010), which may lead to a decrease in relative oxidation level of PQ and thus electron flow back-pressure on PSII (Hill et al., 2014).

In summary, we suggest that under conditions when the chlorophyll fluorescence signals may be complex to interpret i.e., due to the vertical light heterogeneity in coral tissues (Wangpraseurt et al., 2012), P700 kinetics measurements performed in the NIR region may serve as a whole tissue marker for operation of both PSII and PSI and a non-invasive stress indicator of photosynthetic efficiency of coral endosymbionts (the combination of P700 and chlorophyll fluorescence methods 
to understand intersystem PSII-PSI electron transfer properties are shown in Figure S2). How these current findings under transient and rapid (acute) heat stress ultimately apply to more prolonged heat stress events that drive coral bleaching in nature will be an important next question to investigate, as is, for example, whether the transient perturbation of intersystem electron flow, represented by the P700 kinetics signal, provides a sensitive marker of photosynthetic activity under other sub-lethal stress conditions as well. It has to be noted that during prolonged stress exposure, the P700 signal might also be influenced by biooptical/physiological alterations of coral tissues (e.g., symbiont expulsion, changes in pigment concentrations across the tissue) that need to be investigated further. Physiological phenomena of the coral holobiont such as tentacle movement and/or contraction could have occurred in the experimental timeframe applied in the current study, and it may have influenced the cross-section and thus light availability within the coral tissues. However, we suggest that such impacts are minimal, because the functional absorption cross-section of PSII was found unchanged (Figure 7B). It also remains to be investigated whether P700 redox signal can be assigned as a functional trait, as it has been shown that chlorophyll fluorescence parameters can be associated with the different Symbiodinium genetic types as photobiological traits (Suggett et al., 2015; Goyen et al., 2017).

Finally, our results are in agreement with earlier observations (Jones et al., 1998; Lilley et al., 2010; Bhagooli, 2013; Hill et al., 2014) that a general weakness in corals (potentially leading to coral bleaching) could be the heat sensitivity of the Type II Rubisco, which causes partial inhibition of the Calvin-Benson cycle and $\mathrm{CO}_{2}$ fixation, although the direct effect of acute heat stress on the Rubisco and on the whole photosynthetic productivity remains to be investigated. Under these circumstances, as indicated here, there may be side effects on cyclic electron transport and the Mehler-AscorbatePeroxidase (MAP) pathway. Recent works (Reynolds et al., 2008; Roberty et al., 2014; Aihara et al., 2016) have indicated the possibility that singlet oxygen production is generated when PQ pool is reduced, i.e., the relative size of oxidized PQ pool is smaller (and thus charge recombination in PSII reaction centers is promoted), which may be a primary factor in coral bleaching (Vass, 2012; Rehman et al., 2016). Nevertheless, these effects

\section{REFERENCES}

Aihara, Y., Takahashi, S., and Minagawa, J. (2016). Heat induction of cyclic electron flow around photosystem I in the symbiotic dinoflagellate Symbiodinium. Plant physiol. 171, 522-529. doi: 10.1104/pp.15.01886

Ainsworth, T. D., Thurber, R. V., and Gates, R. D. (2010). The future of coral reefs: a microbial perspective. Trends Ecol. Evol. 25, 233-240. doi: 10.1016/j.tree.2009.11.001

Anthony, K., Connolly, S. R., and Hoegh-Guldberg, O. (2007). Bleaching, energetics, and coral mortality risk: effects of temperature, light, and sediment regime. Limnol. Oceanogr. 52, 716-726. doi: 10.4319/lo.2007.52. 2.0716

Bhagooli, R. (2013). Inhibition of Calvin-Benson cycle suppresses the repair of photosystem II in Symbiodinium: implications for coral bleaching. Hydrobiologia 714, 183-190. doi: 10.1007/s10750-013-1535-4 have to be documented individually in corals, where it is known that there are varied responses to similar acute thermal stress scenarios (Downs et al., 2013; Gardner et al., 2017). It is entirely possible that despite the "Achilles Heel" of a heat sensitive Rubisco, different Symbiodinium types have evolved different strategies to cope with this problem, and that the diversity of these strategies account for the different heat sensitivities of corals to coral bleaching.

\section{AUTHOR CONTRIBUTIONS}

MS, AL, IV, and WC planned the study. MS and AZ collected the data. MS, AL, AZ, IV, LS, DS, BO, and WC interpreted and analyzed the data. PR and WC provided consumables, reagents and tools. All authors contributed to drafting, critical commenting the manuscript and approved it for publication.

\section{FUNDING}

This work was supported by the award of Australian Research Council Discovery Project (ARC DP120101360) to WC and Future Fellowship (FT130100202) to DS. IV and LS were partly supported by a grant from the Hungarian National Research, Development and Innovation Office (NN110960). Construction of the prototype LIFT-FRRf instrument was supported by a development grant to BO from the University of Wollongong.

\section{ACKNOWLEDGMENTS}

The authors thank Dr. Zbigniew Kolber for his advice on LIFTFRRf data analysis, Paul Brooks, Graeme Poleweski and David Hughes for maintenance of UTS coral tanks, Drs. Ross Lilley, Mathieu Pernice, Dimitri Tolleter and Duncan Fitzpatrick for fruitful discussions.

\section{SUPPLEMENTARY MATERIAL}

The Supplementary Material for this article can be found online at: http://journal.frontiersin.org/article/10.3389/fmars. 2017.00269/full\#supplementary-material

Brodersen, K. E., Lichtenberg, M., Ralph, P. J., Kühl, M., and Wangpraseurt, D. (2014). Radiative energy budget reveals high photosynthetic efficiency in symbiont-bearing corals. J. R. Soc. Int. 11:20130997. doi: 10.1098/rsif.2013.0997

Cardol, P., Forti, G., and Finazzi, G. (2011). Regulation of electron transport in microalgae. Biochim. Biophys. Acta 1807, 912-918. doi: 10.1016/j.bbabio.2010.12.004

Downs, C., McDougall, K. E., Woodley, C. M., Fauth, J. E., Richmond, R. H., Kushmaro, A., et al. (2013). Heat-stress and light-stress induce different cellular pathologies in the symbiotic dinoflagellate during coral bleaching. PLoS ONE 8:e77173. doi: 10.1371/journal.pone.0077173

Enríquez, S., Méndez, E. R., and Iglesias-Prieto, R. (2005). Multiple scattering on coral skeletons enhances light absorption by symbiotic algae. Limnol. Oceanogr. 50, 1025-1032. doi: 10.4319/lo.2005.50.4.1025

Fan, D.-Y., Fitzpatrick, D., Oguchi, R., Ma, W., Kou, J., and Chow, W. S. (2016a). Obstacles in the quantification of the cyclic electron flux 
around Photosystem I in leaves of C3 plants. Photosyn. Res. 129, 239-251. doi: 10.1007/s11120-016-0223-4

Fan, D.-Y., Ye, Z.-P., Wang, S.-C., and Chow, W. S. (2016b). Multiple roles of oxygen in the photoinactivation and dynamic repair of Photosystem II in spinach leaves. Photosyn. Res. 127, 307-319. doi: 10.1007/s11120-015-0185-y

Gardner, S. G., Raina, J.-B., Ralph, P. J., and Petrou, K. (2017). Reactive oxygen species (ROS) and dimethylated sulphur compounds in coral explants under acute thermal stress. J. Exp. Biol. 220, 1787-1791. doi: 10.1242/jeb.153049

Gorbunov, M. Y., Kolber, Z. S., Lesser, M. P., and Falkowski, P. G. (2001). Photosynthesis and photoprotection in symbiotic corals. Limnol. Oceanogr. 46, 75-85. doi: 10.4319/lo.2001.46.1.0075

Goyen, S., Pernice, M., Szabó, M., Warner, M. E., Ralph, P. J., and Suggett, D. J. (2017). A molecular physiology basis for functional diversity of hydrogen peroxide production amongst Symbiodinium spp. (Dinophyceae). Mar. Biol. 164:46. doi: 10.1007/s00227-017-3073-5

Hennige, S. J., Smith, D. J., Perkins, R., Consalvey, M., Paterson, D. M., and Suggett, D. J. (2008). Photoacclimation, growth and distribution of massive coral species in clear and turbid waters. Mar. Ecol. Prog. Ser. 369, 77-88. doi: $10.3354 /$ meps07612

Hill, R., Brown, C. M., DeZeeuw, K., Campbell, D. A., and Ralph, P. J. (2011). Increased rate of D1 repair in coral symbionts during bleaching is insufficient to counter accelerated photo-inactivation. Limnol. Oceanogr. 56, 139-146. doi: 10.4319/lo.2011.56.1.0139

Hill, R., Larkum, A. W. D., Prasil, O., Kramer, D. M., Szabó, M., Kumar, V., et al. (2012). Light-induced dissociation of antenna complexes in the symbionts of scleractinian corals correlates with sensitivity to coral bleaching. Coral Reefs 31, 963-975. doi: 10.1007/s00338-012-0914-Z

Hill, R., Larkum, A. W., Frankart, C., Kühl, M., and Ralph, P. J. (2004a). Loss of functional Photosystem II reaction centres in Zooxanthellae of corals exposed to bleaching conditions: using fluorescence rise kinetics. Photosyn. Res. 82, 59-72. doi: 10.1023/B:PRES.0000040444.41179.09

Hill, R., and Ralph, P. J. (2005). Diel and seasonal changes in fluorescence rise kinetics of three scleractinian corals. Funct. Plant Biol. 32, 549-559. doi: 10.1071/FP05017

Hill, R., and Ralph, P. J. (2008). Dark-induced reduction of the plastoquinone pool in zooxanthellae of scleractinian corals and implications for measurements of chlorophyll a fluorescence. Symbiosis 46, 45-56.

Hill, R., Schreiber, U., Gademann, R., Larkum, A. W. D., Kühl, M., and Ralph, P. J. (2004b). Spatial heterogeneity of photosynthesis and the effect of temperatureinduced bleaching conditions in three species of corals. Mar. Biol. 144, 633-640. doi: 10.1007/s00227-003-1226-1

Hill, R., Szabó, M., ur Rehman, A., Vass, I., Ralph, P. J., and Larkum, A. W. (2014). Inhibition of photosynthetic $\mathrm{CO}_{2}$ fixation in the coral Pocillopora damicornis and its relationship to thermal bleaching. J. Exp. Biol. 217, 2150-2162. doi: $10.1242 /$ jeb. 100578

Hill, R., and Takahashi, S. (2014). Photosystem II recovery in the presence and absence of chloroplast protein repair in the symbionts of corals exposed to bleaching conditions. Coral Reefs 33, 1101-1111. doi: 10.1007/s00338-014-1188-4

Hoogenboom, M. O., Campbell, D. A., Beraud, E., Dezeeuw, K., and FerrierPages, C. (2012). Effects of light, food availability and temperature stress on the function of photosystem II and photosystem I of coral symbionts. PLoS ONE 7:e30167. doi: 10.1371/journal.pone.0030167

Hu, Y.-Y., Fan, D.-Y., Losciale, P., Chow, W. S., and Zhang, W.-F. (2013). Wholetissue determination of the rate coefficients of photoinactivation and repair of photosystem II in cotton leaf discs based on flash-induced P700 redox kinetics. Photosyn. Res. 117, 517-528. doi: 10.1007/s11120-013-9822-5

Jia, H., Dwyer, S. A., Fan, D.-Y., Han, Y., Badger, M. R., von Caemmerer, S., et al. (2014). A novel P700 redox kinetics probe for rapid, non-intrusive and whole-tissue determination of photosystem II functionality, and the stoichiometry of the two photosystems in vivo. Physiol. Plant 152, 403-413. doi: $10.1111 / \mathrm{ppl} .12235$

Jones, R., and Hoegh-Guldberg, O. (2001). Diurnal changes in the photochemical efficiency of the symbiotic dinoflagellates (Dinophyceae) of corals: photoprotection, photoinactivation and the relationship to coral bleaching. Plant Cell Environ. 24, 89-99. doi: 10.1046/j.1365-3040.2001. 00648.x

Jones, R. J., Hoegh-Guldberg, O., Larkum, A. W. D., and Schreiber, U. (1998). Temperature-induced bleaching of corals begins with impairment of the $\mathrm{CO}_{2}$ fixation mechanism in zooxanthellae. Plant Cell Environ. 21, 1219-1230. doi: 10.1046/j.1365-3040.1998.00345.x

Jones, R. J., Muller, J., Haynes, D., and Schreiber, U. (2003). Effects of herbicides diuron and atrazine on corals of the Great Barrier Reef, Australia. Mar. Ecol. Prog. Ser. 251, 153-167. doi: 10.3354/meps251153

Kalaji, H. M., Schansker, G., Brestic, M., Bussotti, F., Calatayud, A., Ferroni, L., et al. (2017). Frequently asked questions about chlorophyll fluorescence, the sequel. Photosyn. Res. 132, 13-66. doi: 10.1007/s11120-016-0318-y

Klughammer, C., and Schreiber, U. (1994). An improved method, using saturating light-pulses, for the determination of photosystem-I quantum yield via $\mathrm{P} 700^{+}$. absorbance changes at $830 \mathrm{~nm}$. Planta 192, 261-268. doi: 10.1007/BF01089043

Kolber, Z. S., Prasil, O., and Falkowski, P. G. (1998). Measurements of variable chlorophyll fluorescence using fast repetition rate techniques: defining methodology and experimental protocols. Biochim. Biophys. Acta Bioenerg. 1367, 88-106. doi: 10.1016/S0005-2728(98)00135-2

Kou, J., Oguchi, R., Fan, D.-Y., and Chow, W. S. (2012). The time course of photoinactivation of photosystem II in leaves revisited. Photosyn. Res. 113, 157-164. doi: 10.1007/s11120-012-9743-8

Kou, J., Takahashi, S., Oguchi, R., Fan, D.-Y., Badger, M. R., and Chow, W. S. (2013). Estimation of the steady-state cyclic electron flux around PSI in spinach leaf discs in white light, $\mathrm{CO} 2$-enriched air and other varied conditions. Funct. Plant Biol. 40, 1018-1028. doi: 10.1071/FP13010

Kramer, D. M., and Evans, J. R. (2011). The Importance of energy balance in improving photosynthetic productivity. Plant Physiol. 155, 70-78. doi: $10.1104 /$ pp.110.166652

Krämer, W. E., Schrameyer, V., Hill, R., Ralph, P. J., and Bischof, K. (2013). PSII activity and pigment dynamics of Symbiodinium in two Indo-Pacific corals exposed to short-term high-light stress. Mar. Biol. 160, 563-577. doi: 10.1007/s00227-012-2113-4

Leggat, W., Whitney, S., and Yellowlees, D. (2004). Is coral bleaching due to the instability of the zooxanthellae dark reactions? Symbiosis 37, 137-153.

Lichtenberg, M., Larkum, A. W., and Kühl, M. (2016). Photosynthetic acclimation of Symbiodinium in hospite depends on vertical position in the tissue of the scleractinian coral Montastrea curta. Front. Microbiol. 7:230. doi: $10.3389 /$ fmicb. 2016.00230

Lilley, R. M., Ralph, P. J., and Larkum, A. W. (2010). The determination of activity of the enzyme Rubisco in cell extracts of the dinoflagellate alga Symbiodinium sp. by manganese chemiluminescence and its response to short-term thermal stress of the alga. Plant Cell Environ. 33, 995-1004. doi: 10.1111/j.1365-3040.2010.02121.x

McClanahan, T. (2004). The relationship between bleaching and mortality of common corals. Mar. Biol. 144, 1239-1245. doi: 10.1007/s00227-003-1271-9

Muir, P. R., Wallace, C. C., Done, T., and Aguirre, J. D. (2015). Limited scope for latitudinal extension of reef corals. Science 348, 1135-1138. doi: 10.1126/science.1259911

Oakley, C. A., Schmidt, G. W., and Hopkinson, B. M. (2014). Thermal responses of Symbiodinium photosynthetic carbon assimilation. Coral Reefs 33, 501-512. doi: 10.1007/s00338-014-1130-9

Oguchi, R., Douwstra, P., Fujita, T., Chow, W. S., and Terashima, I. (2011) Intra-leaf gradients of photoinhibition induced by different color lights: implications for the dual mechanisms of photoinhibition and for the application of conventional chlorophyll fluorometers. New Phytol. 191, 146-159. doi: 10.1111/j.1469-8137.2011.03669.x

Osmond, C. B., Chow, W. S., Wyber, R., Zavafer, A., Keller, B., Muller, O., et al. (2017). Relative functional and optical absorption cross sections of PSII and other photosynthetic parameters monitored in situ, at a distance with a time resolution of a few seconds, using a prototype Light Induced Fluorescence Transient (LIFT) device. Funct. Plant Biol. doi: 10.1071/FP17024. [Epub ahead of print].

Pernice, M., and Levy, O. (2014). Novel tools integrating metabolic and gene function to study the impact of the environment on coral symbiosis. Front. Microbiol. 5:448. doi: 10.3389/fmicb.2014.00448

Ragni, M., Airs, R. L., Hennige, S. J., Suggett, D. J., Warner, M. E., and Geider, R. J. (2010). PSII photoinhibition and photorepair in Symbiodinium (Pyrrhophyta) differs between thermally tolerant and sensitive phylotypes. Mar. Ecol. Prog. Ser. 406, 57-70. doi: 10.3354/meps08571

Ralph, P. J., Schreiber, U., Gademann, R., Kühl, M., and Larkum, A. W. D. (2005). Coral photobiology studied with a new imaging pulse amplitude modulated fluorometer. J. Phycol. 41, 335-342. doi: 10.1111/j.1529-8817.2005.04034.x 
Rehman, A. U., Szabó, M., Deák, Z., Sass, L., Larkum, A., Ralph, P., et al. (2016). Symbiodinium sp. cells produce light-induced intra-and extracellular singlet oxygen, which mediates photodamage of the photosynthetic apparatus and has the potential to interact with the animal host in coral symbiosis. New Phytol. 212, 472-484. doi: 10.1111/nph.14056

Reynolds, J. M., Bruns, B. U., Fitt, W. K., and Schmidt, G. W. (2008). Enhanced photoprotection pathways in symbiotic dinoflagellates of shallow-water corals and other cnidarians. Proc. Natl. Acad. Sci. U.S.A. 105, 13674-13678. doi: 10.1073/pnas.0805187105

Roberty, S., Bailleul, B., Berne, N., Franck, F., and Cardol, P. (2014). PSI Mehler reaction is the main alternative photosynthetic electron pathway in Symbiodinium sp., symbiotic dinoflagellates of cnidarians. New Phytol. 204, 81-91. doi: 10.1111/nph.12903

Roth, M. S. (2014). The engine of the reef: photobiology of the coral-algal symbiosis. Front. Microbiol. 5:422. doi: 10.3389/fmicb.2014.00422

Schansker, G., Toth, S. Z., and Strasser, R. J. (2005). Methylviologen and dibromothymoquinone treatments of pea leaves reveal the role of photosystem $\mathrm{I}$ in the Chl a fluorescence rise OJIP. Biochim. Biophys. Acta Bioenerg. 1706, 250-261. doi: 10.1016/j.bbabio.2004.11.006

Schrameyer, V., Krämer, W., Hill, R., Jeans, J., Larkum, A. W., Bischof, K., et al. (2016). Under high light stress two Indo-Pacific coral species display differential photodamage and photorepair dynamics. Mar. Biol. 163, 1-13. doi: 10.1007/s00227-016-2940-9

Schrameyer, V., Wangpraseurt, D., Hill, R., Kühl, M., Larkum, A. W., and Ralph, P. J. (2014). Light respiratory processes and gross photosynthesis in two scleractinian corals. PLOS ONE 9:e110814. doi: 10.1371/journal.pone.0110814

Strasser, R. J. (1992). The Fo and the OJIP fluorescence rise in higher plants and algae. Regul. Chloroplast Biogenesis. 226, 423-426.

Strasser, R. J., Tsimilli-Michael, M., Qiang, S., and Goltsev, V. (2010). Simultaneous in vivo recording of prompt and delayed fluorescence and $820 \mathrm{~nm}$ reflection changes during drying and after rehydration of the resurrection plant Haberlea rhodopensis. Biochim. Biophys. Acta Bioenerg. 1797, 122-122. doi: 10.1016/j.bbabio.2010.04.365

Suggett, D. J., Goyen, S., Evenhuis, C., Szabó, M., Pettay, D. T., Warner, M. E., et al. (2015). Functional diversity of photobiological traits within the genus Symbiodinium appears to be governed by the interaction of cell size with cladal designation. New Phytol. 208, 370-381. doi: 10.1111/nph.13483

Suggett, D. J., Warner, M. E., Smith, D. J., Davey, P., Hennige, S., and Baker, N. R. (2008). Photosynthesis and production of hydrogen peroxide by Symbiodinium (Pyrrhophyta) phylotypes with different thermal tolerances. J. Phycol. 44, 948-956. doi: 10.1111/j.1529-8817.2008.00537.x

Szabó, M., Wangpraseurt, D., Tamburic, B., Larkum, A. W., Schreiber, U., Suggett, D. J., et al. (2014). Effective light absorption and absolute electron transport rates in the coral Pocillopora damicornis. Plant Physiol. Biochem. 83, 159-67. doi: 10.1016/j.plaphy.2014.07.015
Tóth, S. Z., Schansker, G., and Strasser, R. J. (2007). A non-invasive assay of the plastoquinone pool redox state based on the OJIP-transient. Photosyn. Res. 93, 193-203. doi: 10.1007/s11120-007-9179-8

Vass, I. (2012). Molecular mechanisms of photodamage in the Photosystem II complex. Biochim. Biophys. Acta Bioenerg. 1817, 209-217. doi: 10.1016/j.bbabio.2011.04.014

Wangpraseurt, D., Larkum, A. W., Franklin, J., Szabó, M., Ralph, P. J., and Kühl, M. (2014). Lateral light transfer ensures efficient resource distribution in symbiont-bearing corals. J. Exp. Biol. 217, 489-498. doi: 10.1242/jeb. 091116

Wangpraseurt, D., Larkum, A. W., Ralph, P. J., and Kühl, M. (2012). Light gradients and optical microniches in coral tissues. Front. Microbiol. 3:316. doi: $10.3389 /$ fmicb. 2012.00316

Warner, M., Chilcoat, G., McFarland, F., and Fitt, W. (2002). Seasonal fluctuations in the photosynthetic capacity of photosystem II in symbiotic dinoflagellates in the Caribbean reef-building coral Montastraea. Mar. Biol. 141, 31-38. doi: 10.1007/s00227-002-0807-8

Warner, M. E., Fitt, W. K., and Schmidt, G. W. (1999). Damage to photosystem II in symbiotic dinoflagellates: a determinant of coral bleaching. Proc. Natl. Acad. Sci. U.S.A. 96, 8007-8012. doi: 10.1073/pnas.96. 14.8007

Warner, M. E., Lesser, M. P., and Ralph, P. J. (2010). "Chlorophyll fluorescence in reef building corals," in Chlorophyll a Fluorescence in Aquatic Sciences: Methods and Applications Developments in Applied Phycology, Vol. 4, eds D. J. Suggett, O. Prášil, and M. A. Borowitzka (Dordrecht: Springer), 209-222.

Warner, M. E., and Suggett, D. J. (2016). "The Photobiology of Symbiodinium spp.: linking physiological diversity to the implications of stress and resilience," in The Cnidaria, Past, Present and Future, eds S. Goffredo and Z. Dubinsky (Cham: Springer), 489-509.

Whitney, S. M., Shaw, D. C., and Yellowlees, D. (1995). Evidence that some dinoflagellates contain a Ribulose-1, 5-bisphosphate carboxylase/oxygenase related to that of the \$ alpha \$-proteobacteria. Proc. Biol. Sci. 259, 271-275. doi: $10.1098 / \mathrm{rspb} .1995 .0040$

Conflict of Interest Statement: The authors declare that the research was conducted in the absence of any commercial or financial relationships that could be construed as a potential conflict of interest.

Copyright (C) 2017 Szabó, Larkum, Suggett, Vass, Sass, Osmond, Zavafer, Ralph and Chow. This is an open-access article distributed under the terms of the Creative Commons Attribution License (CC BY). The use, distribution or reproduction in other forums is permitted, provided the original author(s) or licensor are credited and that the original publication in this journal is cited, in accordance with accepted academic practice. No use, distribution or reproduction is permitted which does not comply with these terms. 